\title{
Seeds of good anthropocenes: developing sustainability scenarios for Northern Europe
}

\author{
C. Raudsepp-Hearne ${ }^{1}$ (D) G. D. Peterson ${ }^{2}$ - E. M. Bennett ${ }^{1} \cdot$ R. Biggs ${ }^{2,3} \cdot$ A. V. Norström ${ }^{2} \cdot$ L. Pereira $^{3} \cdot$ J. Vervoort $^{4,5}$. $^{2}$ \\ D. M. Iwaniec ${ }^{6} \cdot$ T. McPhearson $^{2,7} \cdot$ P. Olsson ${ }^{2} \cdot$ T. Hichert $^{3,8} \cdot$ M. Falardeau ${ }^{1} \cdot$ A. Jiménez Aceituno ${ }^{2}$
}

Received: 13 November 2018 / Accepted: 24 June 2019 / Published online: 9 July 2019

(c) The Author(s) 2019

\begin{abstract}
Scenario development helps people think about a broad variety of possible futures; however, the global environmental change community has thus far developed few positive scenarios for the future of the planet and humanity. Those that have been developed tend to focus on the role of a few common, large-scale external drivers, such as technology or environmental policy, even though pathways of positive change are often driven by surprising or bottom-up initiatives that most scenarios assume are unchanging. We describe an approach, pioneered in Southern Africa and tested here in a new context in Northern Europe, to developing scenarios using existing bottom-up transformative initiatives to examine plausible transitions towards positive, sustainable futures. By starting from existing, but marginal initiatives, as well as current trends, we were able to identify system characteristics that may play a key role in sustainability transitions (e.g., gender issues, inequity, governance, behavioral change) that are currently under-explored in global environmental scenarios. We suggest that this approach could be applied in other places to experiment further with the methodology and its potential applications, and to explore what transitions to desirables futures might be like in different places.
\end{abstract}

Keywords Scenarios $\cdot$ Transformation $\cdot$ Sustainability $\cdot$ Anthropocene $\cdot$ Futures

\section{Introduction}

\section{Scenarios to explore the anthropocene}

Handled by Jeremy Brooks, Ohio State University School of Environment and Natural Resources, United States.

Electronic supplementary material The online version of this article (https://doi.org/10.1007/s11625-019-00714-8) contains supplementary material, which is available to authorized users.

C. Raudsepp-Hearne

ciara.raudsepp-hearne@mail.mcgill.ca

1 McGill School of Environment and Department of Natural Resource Sciences, McGill University, Ste-Anne-de-Bellevue, Montreal, QC H9X3V9, Canada

2 Stockholm Resilience Centre, Stockholm University, Stockholm, Sweden

3 Centre for Complex Systems in Transition, Stellenbosch University, 19 Jonkershoek Road, Stellenbosch 7600, South Africa

4 Copernicus Institute of Sustainable Development, Utrecht University, Utrecht, The Netherlands
As we look to the future of the planet, we are confronted with a complex set of intertwined sustainability challenges and high uncertainty. The anthropocene is characterized by rapidly changing, interconnected global systems and socialecological complexity that make it difficult to anticipate and

5 Environmental Change Institute, Oxford University Centre for the Environment, Oxford, UK

6 Urban Studies Institute, Andrew Young School of Policy Studies, Georgia State University, 55 Park Place NE 849E, Atlanta, GA 30303, USA

7 Urban Systems Lab, The New School, 79 Fifth Avenue, 16th Fl, New York, NY 10003, USA

8 Hichert and Associates Pty Ltd., 9 Cylnor Street, Somerset West 7130, South Africa 
respond to evolving and emerging issues (Liu et al. 2015). Climate change, inequity, biodiversity loss, changes in biogeochemical cycles, and other global changes threaten the planet and human life (Steffen et al. 2015). At the same time, many individuals and societies are seeking ways to address these challenges and improve their well-being. Because of the large uncertainty about how these complex challenges and potential solutions will play out, scenarios are often used as a tool to investigate assumptions, uncertainties, and outcomes associated with alternative trajectories for our planet and societies.

A scenario is a plausible description of how the future may develop, based on a coherent and internally consistent set of assumptions about key driving forces and their relationships (Millennium Ecosystem Assessment (MA) 2003). Scenario development has been used in global environmental assessments to explore nonlinearities in systems, focus scientific investigation, integrate different models and data, and evaluate policies (Kok et al. 2017). Environmental scenarios are typically built on extrapolations of the past or explorations of currently developing trends of interest. For example, the shared socioeconomic pathways explore a variety of anticipated changes in energy and land use (O'Neill et al. 2014) or Millennium Ecosystem Assessment scenarios explore trends in global development or use of technology (Millennium Ecosystem Assessment (MA) 2005). However, extrapolations of trends do not capture the dynamics that can lead to their reversal, nor are they able to capture the kind of radical transformative change required for a more sustainable future (Temper et al. 2018; Scoones et al. 2018). For example, after decades of rise, some countries appear to have passed 'peak car use' and 'peak meat consumption' (Seppelt et al. 2014). Capturing the possibility of such trends requires scenario approaches that consider how social-ecological dynamics can change (Peterson et al. 2003).

Scenario approaches have been criticized for a number of other weaknesses, including a failure to incorporate sufficient system complexity (Feldman and Biggs 2012; Van Vuuren et al. 2012), a focus on global stories that omit local processes, drivers, and values, and the omission of important cross-scale dynamics and social-ecological feedbacks (Cumming et al. 2005; Rosa et al. 2017). Importantly, most environmental scenarios of today are missing the impact of cultural diversity, political economy, trust, and other features of the world that are inherently difficult to model, but critical to understanding how the future will unfold (Westley 2017; Bennett et al. 2016). These features are often left out because they are difficult to quantify and rarely feature in scenario models (Cumming et al. 2005; Booth et al. 2016). By failing to capture these elements, scientists reduce the range of possible pathways and ultimately people's agency to shape the future (Wiebe et al. 2018).
Here, we describe a novel participatory scenario approach that responds to demands for more relevant regional scenarios and that feature previously unexplored drivers of the future. Our goals are to complement existing scenario methods by:

1. Exploring a novel set of drivers that are not currently used in scenarios because they are indirect, difficult to quantify, or because they are assumed to be constants. Exploring these drivers, even if they aren't quantifiable with current methods, is an important step forward for scenario development, highlighting areas where new quantitative models are needed to empirically explore key overlooked variables.

2. Expanding the scenario tool kit by testing a "seedsbased" method for developing scenarios that are fundamentally different from existing scenarios and report back on the successes of this new method as well as areas that require further work. We describe the process and unique outcomes of the exercise in Northern Europe, reflect on what we observed and learned, and suggest promising avenues of research for improving understanding of transitions towards positive futures. We also derive lessons for how our novel scenario development approach could be used to enrich and challenge global scenario development efforts, including by providing novel hypotheses of change that could be tested in quantitative models.

\section{Methods and process}

Our scenario approach purposefully focuses on positive futures because inspirational visions can be key components of transformations to sustainability (Wiek and Iwaniec 2014), and can articulate, coordinate, and encourage actions that help build desirable futures (Hebinck et al. 2018; McPhearson et al. 2017). The most unique aspect of the approach is that it builds scenarios from 'seeds' of positive futures, i.e., real-world agents of current social-ecological transformation that are currently marginal, but have the potential to grow in impact (Bennett et al. 2016; Pereira et al. 2018a). These 'seeds' are taken from the 'seeds of good anthropocenes' database (https://goodanthropocenes.net/). A more sustainable and just future will, by necessity, build on the present, and is likely to be composed of many elements already in existence, albeit reconfigured and combined with new participants, ideas, infrastructure, and technologies (Bai et al. 2016). While the concept of a 'good' Anthropocene is contested and potentially problematic (Preiser et al. 2017), we have a pluralistic and open approach to this notion while also not underestimating the gravity of the challenges the Anthropocene offers. 
The seed scenario workshop 'Envisioning and Creating a Good Anthropocene in Northern Europe' took place from June 6-9, 2017 outside of Stockholm, Sweden. This workshop further developed an approach to scenario development that was first implemented in southern Africa and is described in detail in Pereira et al. (2018a). The Stockholm workshop team included two scientists from the southern African team and used the same facilitator for the workshop. In this process, we added a step to the scenario process that analyzed and compared the scenarios, to the method described in Pereira et al. (2018a).

The 26 participants at the Stockholm workshop were selected to create four small but diverse groups. While participant selection has a strong influence on scenario content-and we discuss how this can be managed in the discussion- this scenario exercise was designed to explore methodology and required a diversity of knowledge holders rather than a specific set of stakeholders to be represented. Each of the four groups consisted of scientists, seed representatives, and an artist. There was also a facilitator for the process. The seed representatives were key individuals from a diverse set of sustainability innovations (see Table 1). Artists were present to assist with diverse creative engagement with futures, and included a science fiction author, a graphic artist, a designer, and a science writer. Scientists included both social and natural scientists, and included scenario experts and experts in the theory and practice of social-ecological transformation.

The participants worked in four groups over the course of 3 days to develop scenarios. Each group received three 'seeds' from the seeds of good anthropocenes database (Bennett et al. 2016), including two social, ecological, or

Table 1 List of seeds used to develop Northern Europe scenarios

\begin{tabular}{|c|c|c|}
\hline Seed name & Description & Website \\
\hline 15-M movement & $\begin{array}{l}\text { Anti-austerity movement in Spain led by a network of ad } \\
\text { hoc citizen coalitions to help push back and challenge } \\
\text { specific government actions }\end{array}$ & $\begin{array}{l}\text { https://en.wikipedia.org/wiki/Anti-austerity_movem } \\
\text { ent_in_Spain }\end{array}$ \\
\hline Health in harmony & $\begin{array}{l}\text { Health in Harmony works in Indonesia to address human } \\
\text { health and deforestation }\end{array}$ & http://www.healthinharmony.org/about/mission-history/ \\
\hline Transition towns & $\begin{array}{l}\text { Grassroots community project that seeks to build } \\
\text { resilience in response to peak oil, climate change, and } \\
\text { economic instability, by creating local groups that } \\
\text { uphold the values of the transition network }\end{array}$ & $\begin{array}{l}\text { https://www.youtube.com/watch?v=rQF09NG00V } \\
8 \# t=901.619604\end{array}$ \\
\hline Snowchange cooperative & $\begin{array}{l}\text { Organization in Finland devoted to the advancement } \\
\text { of Northern indigenous traditions, knowledge, and } \\
\text { culture. Large focus on climate change }\end{array}$ & http://www.snowchange.org/ \\
\hline The finance innovation lab & $\begin{array}{l}\text { Aims to be a catalyst for the transition to a better finan- } \\
\text { cial system. Works with innovators and early adopters } \\
\text { changing the financial system }\end{array}$ & http://financeinnovationlab.org/about-us/our-strategy/ \\
\hline Trees for life & $\begin{array}{l}\text { Works to revive and 'rewild' the Scottish Caledonian } \\
\text { rainforest, regenerating ecological richness, diversity } \\
\text { and productivity to provide opportunities for people } \\
\text { living there to achieve spiritual, and economic develop- } \\
\text { ment }\end{array}$ & http://treesforlife.org.uk/ \\
\hline Closed loop farming & $\begin{array}{l}\text { Zero-waste, closed loop farming in Sweden and other } \\
\text { places }\end{array}$ & \\
\hline MEGA game & $\begin{array}{l}\text { A gamified web platform and smartphone app that gives } \\
\text { you the knowledge, skills, and power to create a sus- } \\
\text { tainable world by playing for impact }\end{array}$ & http://megageneration.com/ \\
\hline Memphis meats & $\begin{array}{l}\text { Developing real meat from animal cells, without the } \\
\text { need to feed, breed and slaughter actual animals }\end{array}$ & http://www.memphismeats.com/media/ \\
\hline Vertical forests & $\begin{array}{l}\text { A model of vertical densification of nature within the } \\
\text { city that operates in relation to policies for reforesta- } \\
\text { tion and naturalization of large urban and metropolitan } \\
\text { borders }\end{array}$ & $\begin{array}{l}\text { http://www.stefanoboeriarchitetti.net/en/portfolios/bosco } \\
\text {-verticale/ }\end{array}$ \\
\hline De-extinction & $\begin{array}{l}\text { De-extinction, resurrection biology, or species revival- } \\
\text { ism, is the process of creating extinct or endangered } \\
\text { organisms, through cloning or selective breeding }\end{array}$ & $\begin{array}{l}\text { http://www.nationalgeographic.com/magazine/2013/04/ } \\
\text { species-revival-bringing-back-extinct-animals/ }\end{array}$ \\
\hline Self-driving cars & $\begin{array}{l}\text { Self-driving cars are vehicles that are capable of navigat- } \\
\text { ing through a changing environment without human } \\
\text { input }\end{array}$ & \\
\hline
\end{tabular}


social-ecological projects/initiatives and one 'technology seed' (See Table 1 for list of seeds, full descriptions in S2). The seeds were selected for relevance to Northern Europe and diversity in the types of challenges they address.

The Seeds approach to scenarios is based on an emerging understanding of how change occurs in complex adaptive social-ecological systems, or SES (Pereira et al. 2018a) that integrates two key existing frameworks: the sociotechnical transitions framework, and the stages of social-ecological transformations (Moore et al. 2014). Macroscale change in SES comprises three interconnected phases: preparation, navigating the transition, and consolidation. During the workshop we used a variety of approaches to develop pathways through these phases.

The workshop itself was divided into four activities: (1) elaboration of 'Future Wheels' to develop each set of seeds into the skeleton of an internally plausible vision of the future; (2) backcasting and forecasting using a 'Three Horizons' framework to iteratively develop a story of how the future described by the future wheel came to be (i.e., the scenario pathway), including exploration of how specific system elements declined or grew, what conflicts arose, and what events or supporting elements were needed to bring about change; (3) creative storyline development to summarize the scenario and present the essential elements to the larger group; (4) analysis and comparison of scenarios.

The first exercise for the groups was to construct Future Wheels around each of the three seeds, a modified version of the Mānoa method of scenario development (adapted from Schultz 2015). To do this, each seed was imagined as a mature version of itself that has been institutionalized and is now (in the imagined future) mainstream. The time horizon for the scenarios was set at about 100 years to allow for large-scale, transformative change to occur. The mature vision of each seed forms the center of a Future Wheel, with primary and secondary (social, technological, economic, environmental, political, and value) consequences of the mature seed described around this center (see Fig. 1). The wheel helps in developing the systemic connections between change and its implications for society and the environment. After the wheels were developed for each of three seeds, the groups worked to identify interactions among the three wheels, especially focusing on conflicts and synergies among the trends associated with each wheel, as well as impacts of seeds on other seeds. The result of this exercise was a well-developed, rich vision of the future that explains

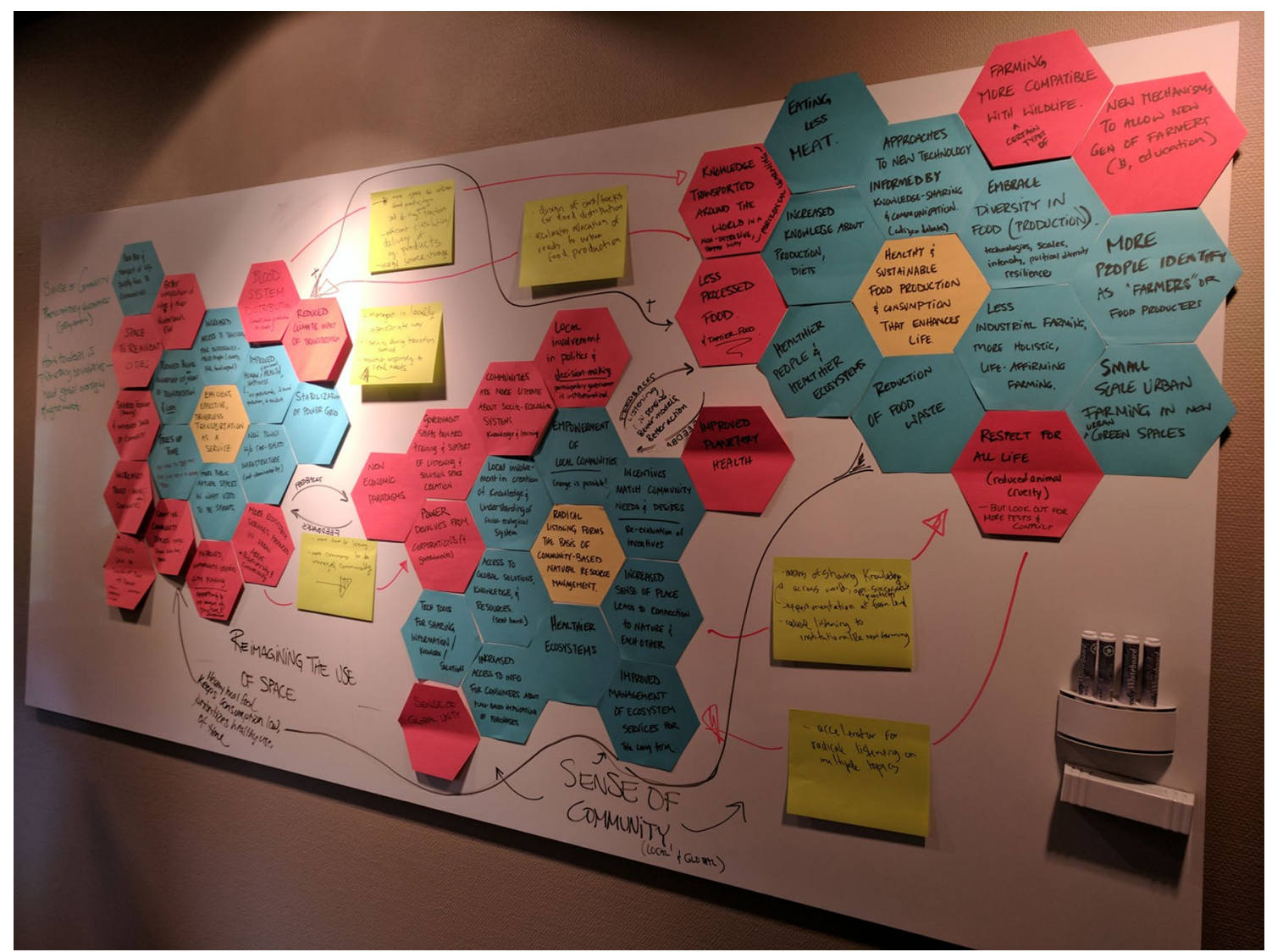

Fig. 1 Future wheels for three seeds. The seeds described in their mature forms (i.e., imagining that they are mainstream) are the center yellow hexagons, with first-order impacts in blue and second-order impacts in red 
how the seeds interact to form a plausible and internally consistent future that represents a 'good Anthropocene'.

The second exercise involved using a modified 'Three Horizons' approach to develop a pathway to the vision described in the first exercise. Three Horizons is a graphical approach for exploring how the features that dominate the world can change over time (Sharpe et al. 2016). This framework asks people to consider how existing dominant patterns and paradigms of the "first horizon" (the world as it is now) could shift to fundamentally new patterns of the third horizon (the future) - through a period of transition in the second horizon. We modified and adapted the Three Horizons framework to flesh out a development pathway from the seeds as they are now to the future vision of the seeds in their 'mature' form. The growth and interaction of seeds were used to explore how currently marginal ideas and practices might grow into dominant ones in the third horizon. Participants were then asked to refine this trajectory by looking backward from the future (i.e., from the mature vision of the seeds) to the present and by imagining what parts of today's world would have to become less important- to stop being dominant-for this trajectory to occur. Finally, conflicts that arise between the growth of the seeds and the decline of dominant elements of the present world were explored, as well as the types of enabling conditions that would be necessary to resolve these conflicts. Iteration was necessary between discussions about each of the horizons to develop internal consistency.

The third exercise required the groups to articulate the full scenario, including both the final vision of the future as well as how Northern Europe transitioned from the present to that future. Groups were asked to describe and communicate their scenario to the rest of the workshop participants. Each of the four groups took creative approaches to this activity, resulting in four unique presentations of the scenarios. This activity was used to deepen and reflect upon the scenario narrative.

Finally, the resulting scenarios were analyzed by comparing specific elements across the four scenario narratives. The analysis process was initiated at the workshop, where participants broke into groups with at least one individual from each scenario to identify commonalities and differences related to story elements and assumptions. The workshop team then built on the preliminary results by organizing elements included in each scenario into tables and systematically reviewing whether and how each element was represented in each scenario, describing commonalities and differences. The scenario narratives were analyzed to compare how each scenario explained the transition from the present to the future: (1) how did currently marginal elements of systems grow or proliferate into the future; (2) how did mainstream elements of present systems decline in the future; (3) how did current and future elements conflict during the transition; and (4) what were the enabling conditions needed to achieve transition from the present to the future. The scenario narratives were then rewritten in a consistent way, which also identified common elements and differences among the scenarios.

\section{Results}

\section{Scenario descriptions}

The full descriptions of the four scenarios (Global Knowledge for Local Management, Wild and Tele-connected, Creative and Collaborative, and The League of Cooperative Communities) are found in the supplementary material (S1) and summarized here.

\section{Commonalities and differences among the Northern European scenarios}

\section{Key story elements}

In many regards, the four scenarios had much in common, even though they were developed independently from one another, and with quite different starting points (See Fig. 2 for a summary of unique and common features of the scenarios). Decentralization of power featured in all four scenarios. All scenarios imagined a decline in the power of the nationstate and multi-national companies, in which capitalism and national state power were no longer dominant, but power rested in decentralized communities, networks, and cooperatives, with substantial decreases in wealth inequality and ownership of private property. Decentralization of energy production and distribution was also a common feature.

Another element common to all scenarios was the rewilding of urban areas to make them both greener and more connected to surrounding rural landscapes. Closer connections between people and nature were facilitated in all scenarios by technological change and changes in human values, which occurred primarily through increased local stewardship. All scenarios envisioned that many current large-scale environmental challenges such as climate change and sustainable food production were being successfully stabilized or managed.

Across all four scenarios, there was a shift in mainstream values away from consumption, individualism, ownership, and anthropocentrism towards community living, local democracy, cooperation, social safety nets (e.g., health care and basic income to support everyone), and a focus on sharing services, rather than ownership, such as of tools or private cars. People generally engaged in less wage labor and spent more time with family, friends, and communities. 
Fig. 2 The figure's outer panels list unique elements described in each of the scenarios, and the central panel lists common elements that were described in all or most of the scenarios

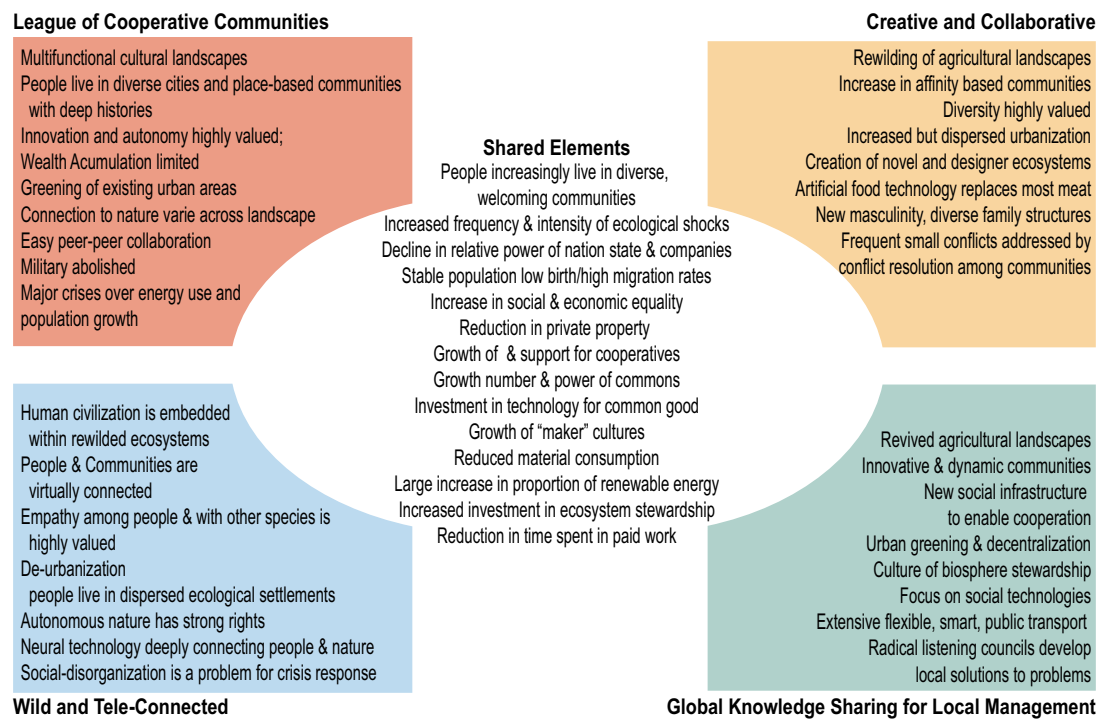

Notable differences among scenarios included the level of dominance, role, and use of technology in the future, as well as differences in social organization, political organization, and the amount of change in gender roles. All scenarios envisioned the use of technology to share knowledge and information within information commons, as well as the dominance of low carbon energy sources. However, scenarios differed in their approach to food production, with the creative and collaborative scenario (C\&C) imagining artificial food leading to revolutionary changes in agriculture while other scenarios envisioned increased local collaborative farming. Wild and Tele-connected (W\&T) imagined radical changes in humanity in which people modified themselves using imagined technologies that enabled them to connect to each other telepathically, resulting in a world that would not be recognizable today.

\section{Transitions to the future}

While there were many similar elements envisioned across the four scenarios, because each scenario was developed from a unique set of seeds, the transitions to the future differed in important ways. Figure 3 shows the results of the Three Horizons framework exercise (step 2), and identifies what features of today's world each group thought would have to decline to realize the future vision (Horizon 1), how the groups thought their seeds could grow to become mainstream in the future (Horizon 3), and what conflicts and enabling conditions were considered necessary to achieve the transition (Horizon 2).

All groups found it relatively easy to imagine the growth and mainstreaming of seeds that currently exist in the world (Horizon 3). In contrast, all found it difficult to imagine which leverage points would be powerful enough to downgrade what were considered to be negative elements of current realities (e.g., corporate greed, malignant governance, and the treadmill of competition and ever-increasing work) (Horizon 1). Thus, we see that the seeds expand in their influence in fairly similar ways across all scenarios, but the way that current power devolved, breaking the status quo, was quite different across the storylines. Primary drivers of power devolution in different scenarios included active take-over from below (C\&C) dissolution of governments (W\&T), loss of power by corporations (The League of Cooperative Communities (LCC), Global Knowledge for Local Management (GfL), W\&T) and value changes (LCC, GfL, W\&T). These were accompanied by shifts in human behaviors through changing aspirations, preferences, and relationships, which together provided the scaffolding for the envisioned transformations. The empowerment of local communities was a crucial leverage point in all scenarios. For example, in the GfL scenario, the empowerment of local communities was key to many of the changes that came after and was enabled by a crisis that communities were able to deal with better than national governments, whereupon confidence in community governance rose.

Although general mechanisms for shifts were identified eventually, participants found it difficult to explain the details of causal mechanisms that would bring about shifts in values needed to create tight-knit communities, reduced consumption, less time spent looking at screens, and a closer relationship with nature. All four groups developed scenarios that relied on shifts in values (e.g., from individualism to community focus), technology, and crises as leverage points to drive change, which in turn drove further change in values, technology, and other storyline elements (see Fig. 3). In some cases (e.g., C\&C), the reduction of busy, consumption-driven lifestyles was related to increased participation 
a

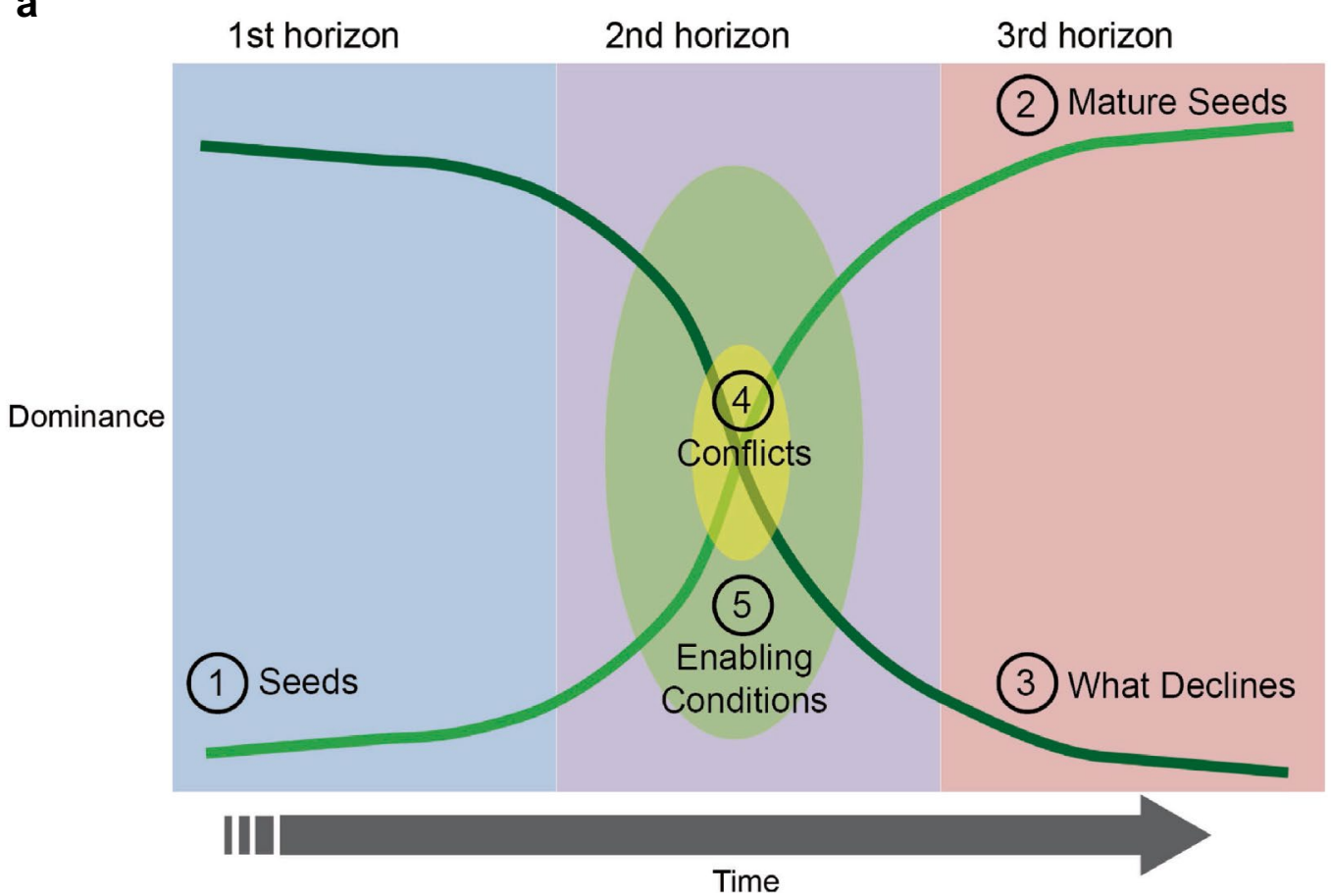

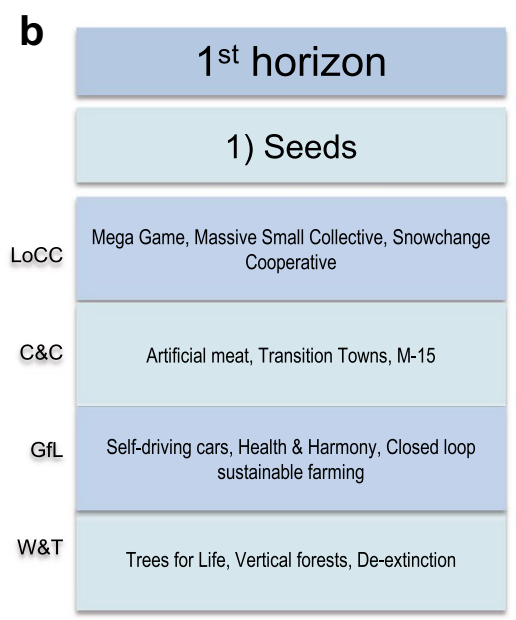

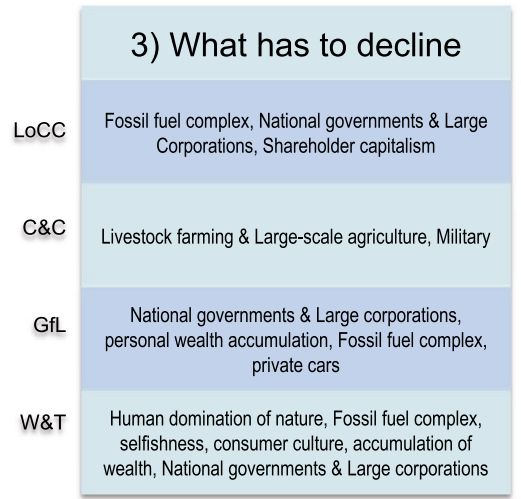

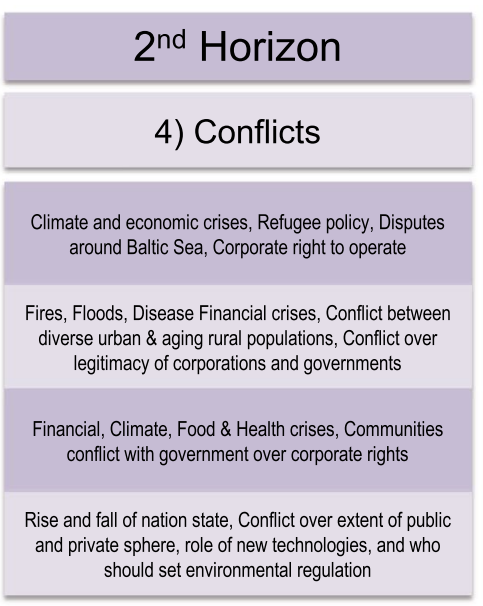

\section{5) Enabling Conditions}

Peer-to-peer web platforms, Technology for networking, publicly-funded investments in cheaper renewables, Value of carbon embedded in economic systems, Divestment from fossil fuels, Product labeling Citizen democracy movements, Embrace of social diversity, New masculinity, Investment in commons, Strong social safety net, Food system disruption, New residents migrate to depopulated rural villages,

Urban planning for people not cars, Investment in commons, Shift in values towards community, Rapid/safe transportation, Corporate divestment

Financial transparency, Rise of 'Green Left', Regulation of industries, Rights for nature, Income cap, Sharing economy, Shift in values towards health \& nature Overcoming divide between humans, nature \& technology

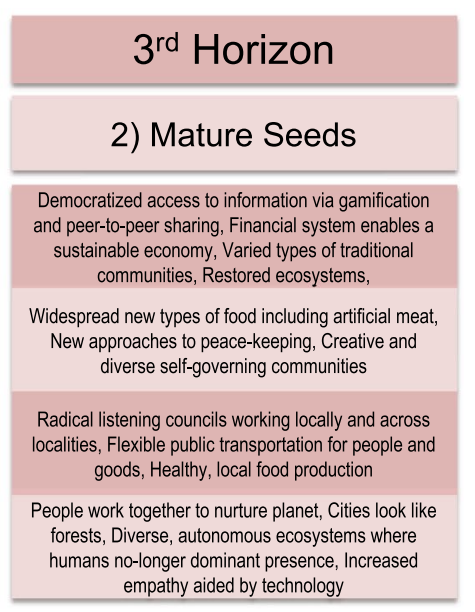

Fig. 3 Results of three horizons work describing transitions from the present to the future. Panel A shows how seeds that are marginal in society: (1) can grow to become mainstream (2), whereas powerful institutions can decline (3). These shifts can lead to societal trans- formation, but generally must pass through times of conflict (4) and require enabling conditions (5). Panel B describes each of these elements in the transitions proposed within the four scenarios that were developed 
in local governance and the sharing economy (enabling individuals to choose not to accumulate goods) and a better social safety net (driven by government interventions).

The described transitions were not smooth in any of the scenarios, and each required some form of crisis to break down existing socio-political and economic regimes and allow for social-ecological seeds to flourish (Fig. 4). Crises that led to radically different governance structures included environmental, population, and food quality crises that led to people wanting, or receiving more power at the local level. Changes in technology also facilitated and enabled devolution of power in a disruptive way. It was unclear in most scenarios the precise leverage point for reducing individual wealth (e.g., taxation, expropriation), which was nevertheless a feature of all four scenarios.

While the purpose was to develop positive scenarios about the future, participants were not entirely utopic in their imagination and identified many conflicts and situations where problematic futures could arise in their storylines. Some of the potential traps that were identified included an inability to manage global challenges, regulation, and conflict with localized government, isolationism, and fragmentation. Most groups thus identified a need for reflective, adaptive governance that responded rapidly and fairly to community issues to limit the likelihood of these pathways from arising. Some groups also identified a need for ways to communicate and collaborate across regions to avoid or address these challenges. Another suggested potential trap was not involving networks of people and institutions in transitions, and instead relying on a less resilient strategy of counting on individuals, 'heroes', or narrow groups of people to bring about change (Bacq and Janssen 2011).

\section{Discussion}

This scenario exercise aimed to develop a set of novel, positive environmental futures for Northern Europe with goals of (1) further developing the 'scenarios from seeds' methodology in a new setting, and (2) using the methodology to help participants explore factors that are not typically central to scenario development but might have important impacts on the future, such as gender dynamics, the way people approach ownership, and behavioral shifts.

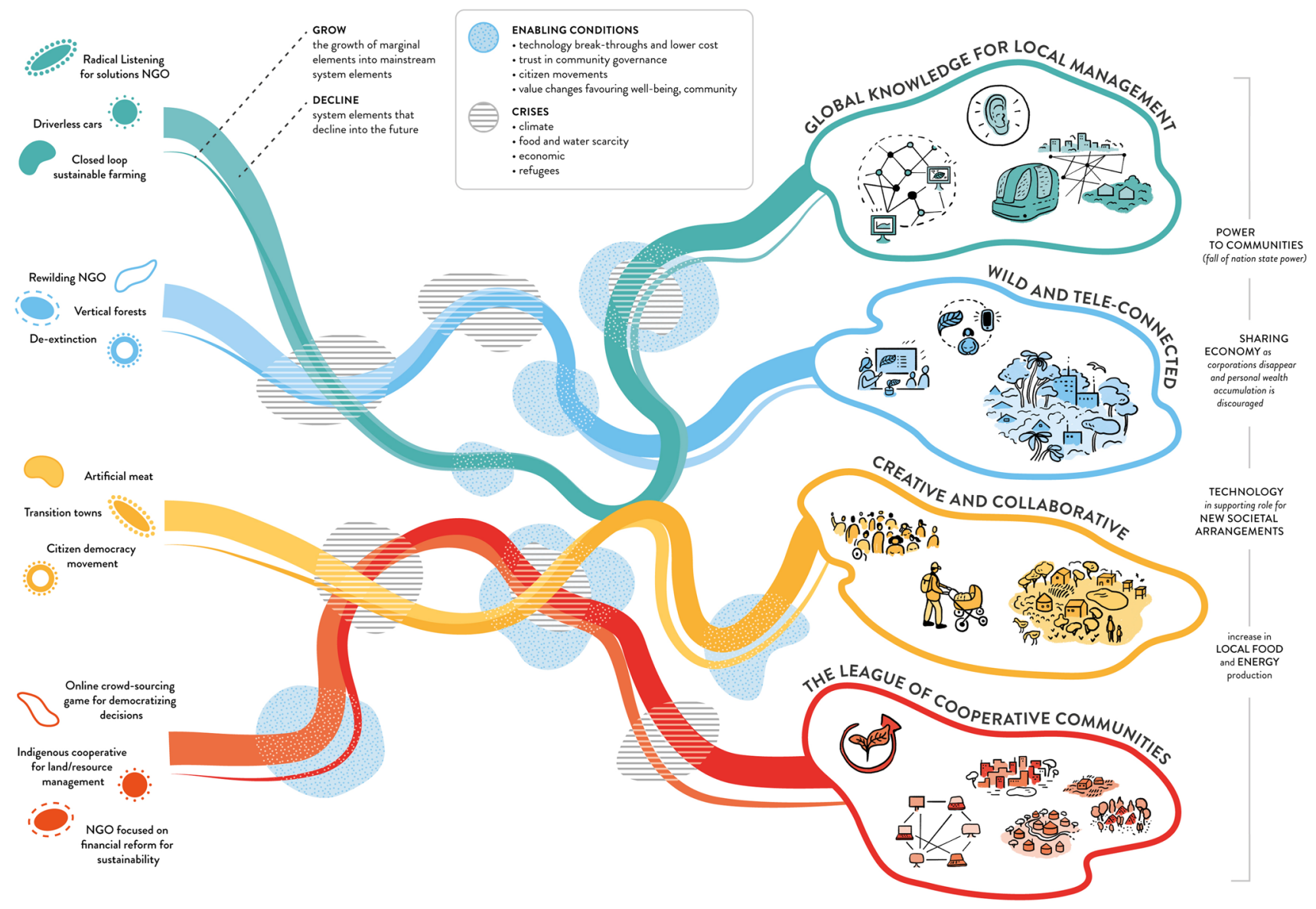

Fig. 4 Process and outcomes of scenarios from seeds exercise for Northern Europe 
Here, we will discuss how the scenarios we developed are different from existing scenarios, and explore the insights we gained about scenario methodology from this process. We then discuss in more detail several potentially important driving factors that we identified through our process that we believe should be the focus of greater attention within sustainability science and future scenario development. We conclude with some suggestions for future scenario development using the seeds methodology.

Scenarios have been used in the global scientific community to consider and plan for possible futures (Nakicenovic et al. 2000; Millennium Ecosystem Assessment (MA) 2005; Riahi et al. 2017). Generally, these scenarios have focused on large-scale, often top-down drivers that are easily and obviously connected to social and ecological futures (Van Vuuren et al. 2012). For example, the Millennium Assessment scenarios varied in whether people in the future were more proactive or more reactive to environmental issues, as well as in the level of interconnectedness of nations-features that can be easily related to the future of key environmental outcomes, such as biodiversity loss or land use change (Millennium Ecosystem Assessment (MA) 2005). More recently, the Shared Socioeconomic Pathways (SSPs) incorporate broad trends in demographic, political, social, cultural, institutional, lifestyle, economic, and technological aspects, and the conditions of ecosystems and ecosystem services that have been affected by human activity such as air and water quality, biodiversity, and ecosystem form and function (O'Neill et al. 2014).

The 'scenarios from seeds' methodology, which is grounded in existing experiments that aim to change the world, focuses on how underlying social features of the world might change, and on the environmental outcomes of this change. A common problem of futurism is that it tends to overestimate the transformative impacts of technology and underestimate the impacts of social changes (Vanderbilt 2015). Implicitly, scenario development efforts often assume that social relationships among people will stay more or less the same as they are today, and that technology or attitudes toward the environment or other obvious environmental drivers (e.g., trade) will drive environmental change. In contrast, our Northern European scenarios explored how current social-ecological seeds (experiments in new ways of doing things) could grow into new forms of social-ecological innovation in Europe (Olsson and Galaz 2012). Thus, the Northern European scenarios featured prominent and important changes in social organization, gender relations, capitalism and the future of the economy, and both governments and governance. This ability of the seeds methods to stimulate consideration of social change was also seen in scenario exercises in the Arctic (Falardeau et al. 2018) and Southern Africa (Pereira et al. 2018a).
The seeds methodology asks participants to look for connections to other initiatives and to explore what enables these connections to succeed and produce synergistic and positive outcomes. These discussions expose the role of social dynamics and elements whose importance are often overlooked in global environmental scenarios. For example, a huge amount of scientific effort has been devoted to answering the question of how much land and food production change is required to feed 10 billion people (Foley et al. 2011; Mueller et al. 2012). The question as posed assumes that historical trends in diet and food preferences will continue as is and not change direction, whereas it is clear that values associated with food are in fact changing (Willett et al. 2019). Such changes will have implications for the future of farming: increasing interest in animal rights, adoption of vegan diets, restrictions of agricultural inputs, and invention of new food technologies could mean that it is possible that the world may be approaching 'peak meat' and a substantial change in food consumption, and possibly production systems, worldwide (Tilman et al. 2011). Similarly, a substantial stream of environmental discourse focuses on reducing individual consumption to create more environmentally friendly societies; however, these conversations generally assume that people will own and use fewer things rather than the alternative of simply sharing more things. An increase in a sharing economy and the 'commons' and an overall decrease in private ownership is a different, often under-considered, solution to overconsumption.

By imagining changes in non-traditional drivers stemming from a wide diversity of initiatives (seeds) that themselves focus on non-traditional drivers, and by identifying plausible pathways to achieve these futures, the seeds scenario process stimulates far-ranging discussions on how social changes could play out in different systems, such as food production or the consumer economy. The exploration of novel pathways in our scenario development exercise demonstrated that large-scale changes in values and behavior are prerequisites to bringing about the scale of positive change that was imagined in the scenarios. Some of these dynamics are already occurring in parts of the world, and could be explored further as inputs into global and regional models that have largely ignored complex social change.

Environmental scientists are drawing overly narrow boundaries around what we think are features of the world that might influence the environment, and the seeds methodology can incorporate these emerging features into scenarios and associated modeling exercises. Features that are likely important to the future of the environment, but not often considered include changes in human biology, media, and the way we work. Humanity appears to be on the verge of being able to substantially modify human nature via neuroscience, genetic engineering, and biological technologies (Harari 2016). Similarly, advances in computer imaging 
and sound editing are enabling rapid translation while also making photography, audio recordings, and video recording easily modifiable to create novel but realistic looking and sounding depictions. These changes are likely to change mass communication and disrupt social consensus (Stover 2018; Helbing et al. 2019). Finally, rapid advancements in artificial intelligence and robotics are shifting the value of labor in ways that could reshape relationships between capital owners, employers, and employees and could fundamentally shift the dynamics of work and capitalism towards post-scarcity egalitarianism or plutocracy (Frase 2016).

Our scenarios are hypothesis generators that suggest new ways that existing models could be used or new models created. Our scenarios identified important roles for processes that have not been widely modeled and are not included in integrated assessment models. The novel drivers that we explored, like changing patterns of ownership, different forms of governance, and new social relations point to interesting areas for modelers to explore in future generations of scenario models. The identification of such variables could be used in combination with the shared socioeconomic pathways (SSPs) (O'Neill et al. 2014) to develop richer crossscale scenarios, or future generations of the SSPs.

\section{Reflections on our methods for future seed method scenario development}

Our Northern European scenarios were designed to explore unexpected or radical futures. This contrasts with many existing scenario methods that aim to explore alternative scenarios that meet the criteria of plausibility. We took this approach because people are often bad at judging what is plausible over longer periods of time (Tetlock 2005) and often real-world events tend to be more radical than even the most novel scenarios and projections into the future (Peterson et al. 2003). The step of developing plausible pathways towards radically different futures can broaden thinking about what is possible and necessary to bring about positive change.

The methods described here and in Pereira et al. (2018a) require further development to address issues that were observed in the Northern European workshop. Further testing and improvement could be made regarding the combination of chosen seeds and process participants. Very similar narratives were developed across scenario groups, and this may be because the seeds selected for the various groups were too similar, or because the values underlying the different seeds were similar. Similar narratives might also have arisen because the participants themselves might all be considered progressive environmentalists with similar northern/western worldviews, despite the diversity of occupations and communities represented in the exercise. Future iterations of the seed approach to scenarios may need to develop mechanisms to ensure that a greater diversity of initiatives and perspectives are included, but in general participants should be tailored to the desired outcomes of the exercise. A similar outcome was experienced at the Southern African workshop (pers. comm. Oonsie Biggs). In both of these cases, the exercises were experimental, focused on developing methods and exploring potential futures in an open-ended and creative way and not geared towards a policy endpoint. Exercises meant to inform decision-making would require that stakeholders with diverse perspectives be included, and that the range of their value systems be represented in the sets of scenarios produced. It would be useful to test how the process responds to a greater variety of value systems that might be in conflict. Falardeau et al. (2018) provide one potential solution for expanding the range of plausible futures discussed by forcing differences among groups based on key uncertainties in the system.

Another improvement to the seeds methodology would be to include steps to build in more discussion around ecological feedbacks, cross-scale dynamics, and the consideration of specific aspects of ecosystems, biodiversity, and ecosystem services. Most of the scenarios focused on social dynamics that resulted in changes to ecosystems or people's interactions with ecosystems, but the groups were challenged to consider feedbacks between ecological and social dynamics in depth. Feedbacks can be inputted into scenarios through discussion and pushback against narrative elements. This could happen as a part of storyline development or as a second step in the process after the first iterations of the storylines are developed.

There are a number of possible next steps for the 'seeds' process to improve on its potential for informing and supporting transformative change at different scales. One next step is to combine this new visioning-focused approach with another mode of scenario development-explorative scenarios focused on testing policies and plans against alternative futures and pathways. The combination of visioning and pathway development on the one hand with challenging scenarios that are developed to offer a diverse set of different conditions against which to examine the feasibility of vision and pathways has proven to be highly productive (Kok and Van Vliet 2011; Vervoort et al. 2014). Our use of the three horizons framework and guidance from transformation research helped us develop transformative scenarios (Pereira et al. 2018a, b). While our approach uses insights from sociotechnical transitions framework, and the stages of social-ecological transformations (Moore et al. 2014), we believe that it would be useful to further integrate insights from transformation and transition research to improve the transformative nature of our scenario method. For example, while participants in the Northern European scenario exercise could identify that corporations, military, and top-down governments were important features in maintaining the 
status quo, it was difficult for participants to imagine processes or pathways that could lead to the decline in these elements, while also avoiding authoritarian or collapsed futures. Enabling scenario development processes that are able to clearly explore and articulate such transformations in a plausible way should be an area of research and integrate theory and knowledge from transformation research that addresses how powerful elements of the current system tend to work hard to keep the dominant system in place (Moore et al. 2014; Loorbach et al. 2017). These enabling scenario processes that build futures literacy through creating positive narratives from diverse perspectives have been recognized as 'transformative spaces' where understanding of potential pathways can enable agency to act against the status quo trajectory and advocate for change (See Pereira et al. 2018c). Many of the difficulties that participants had was in envisioning how to engage with existing power structures and this is where linking to work on radical transformation through resistance could provide useful tools to equip participants with alternative framings of how change can happen (Temper et al. 2018). Having activists and change-makers in the room, together with people representing other sectors like academia or the arts, creates a "safe-enough space" within which to grapple with the complexity of transformative change and how to act to enable such futures to evolve, and is, therefore, a critical contribution to advancing research on transformations to sustainability (Pereira et al. 2018a, c: 32).

The seed scenario method first developed in southern Africa (Pereira et al. 2018a) and tested here in Northern Europe could be applied in other places to see how transitions to desirable futures might be different in different places, and to explore what types of features should be considered as key to developing change. Attempting this exercise in different places and within different communities is essential for getting a greater diversity of ideas incorporated into scenario narratives and discussions around them. It is important to discuss how an ideal future might differ between places such as Northern Europe, Arctic communities, and Southern Africa to eventually scale up to a set of scenarios at the global scale that embraces complexity in the form of synergies, conflicts and connections among regions.

Our experience demonstrated that many system characteristics that are key to sustainability transitions are poorly understood. These are often social features, such as gender issues and inequality, which are difficult to model or even consider in non-quantitative ways. Discussion about transitions to the future can help to identify new kinds of research necessary for achieving the transition to a good anthropocene. Our methodology exposed the complexity of system change and highlighted the need for greater diversity of disciplines and worldviews participating in transformational change work, and for incorporating difficult discussions about societal behavior. Through discussions at the workshop, participants identified the need for ecologists and sustainability scientists to collaborate with behavioral scientists and other experts to look into how transitions towards sustainability can occur in a peaceful and deep way. Possible research priorities identified included solutions-oriented research and analysis of new forms of economic organization (e.g., cooperatives, alternate currencies, and networks), how value changes occur and which value shifts are needed, what conditions are necessary to scale up solutions, and how to make use of scenarios and futures thinking to identify key leverage points for change.

\section{Conclusion}

The anthropocene presents grave challenges for the future of humanity; an important part of exploring solutions to these challenges includes developing positive, but realistic scenarios about a future in which these challenges are addressed. While such positive scenarios have been shown to be useful in helping people think about possible futures, the global community has thus far developed relatively few of them (Bennett et al. 2016; McPhearson et al. 2017; Pereira et al. 2018a, b, c; Rosa et al. 2017). We found that starting from existing, marginal initiatives for change can improve our ability to imagine positive futures and credible pathways to achieve them. The three horizons framework helped focus our discussion on overcoming barriers to achieving these futures, forcing the consideration of pathways of both destruction and growth. Thinking about this sort of transformation is very challenging, but useful to help highlight pathways to potential positive futures.

Funding Funding received from Future Earth Fast Track Initiative and Stockholm Resilience Centre.

Open Access This article is distributed under the terms of the Creative Commons Attribution 4.0 International License (http://creativeco mmons.org/licenses/by/4.0/), which permits unrestricted use, distribution, and reproduction in any medium, provided you give appropriate credit to the original author(s) and the source, provide a link to the Creative Commons license, and indicate if changes were made.

\section{References}

Bacq S, Janssen F (2011) The multiple faces of social entrepreneurship: a review of definitional issues based on geographical and thematic criteria. Entrep Region Dev Int J 23(5-6):373-403. https://doi. org/10.1080/08985626.2011.577242

Bai X, van der Leeuw S, O'Brien K, Berkhout F, Biermann F, Brondizio ES, Cudennec C, Dearing J, Duraiappah A, Glaser M, Revkin A, Steffen W, Syvitski J (2016) Plausible and desirable futures in the Anthropocene: a new research agenda. Glob Environ Chang. https://doi.org/10.1016/j.gloenvcha.2015.09.017 
Bennett EM, Solan M, Biggs R, McPhearson T, Norström AV, Olsson P, Pereira L, Peterson GD, Raudsepp-Hearne C, Biermann F, Carpenter SR, Ellis EC, Hichert T, Galaz V, Lahsen M, Milkoreit M, López BM, Nicholas KA, Preiser R, Vince G, Vervoort JM, Xu J (2016) Bright spots: seeds of a good Anthropocene. Front Ecol. https://doi.org/10.1002/fee.1309

Booth EG, Qiu J, Carpenter SR, Schatz J, Chen X, Kucharik CJ, Loheide SP, Motew MM, Seifert JM, Turner MG (2016) From qualitative to quantitative environmental scenarios: translating storylines into biophysical modeling inputs at the watershed scale. Environ Model Softw 85:80-97

Cumming GS, Alcamo J, Sala O, Swart R, Bennett EM, Zurek M (2005) Are existing global scenarios consistent with ecological feedbacks? Ecosystems 8:143-152

Falardeau M, Raudsepp-Hearne C, Bennett EM (2018) A novel approach for co-producing positive scenarios that explore agency: case study from the Canadian Arctic. Sustain Sci. https://doi. org/10.1007/s11625-018-0620-z

Feldman S, Biggs S (2012) The politics of international assessments: the IAASTD process, reception and significance. J Agrar Chang 12:144-169. https://doi.org/10.1111/j.1471-0366.2011.00333.x

Foley JA, Ramankutty N, Brauman KA, Cassidy ES, Gerber JS, Johnston M, Mueller ND, O'Connell C, Ray DK, West PC, Balzer C, Bennett EM, Carpenter SR, Hill J, Monfreda C, Polasky S, Rockström J, Sheehan J, Siebert S, Tilman D, Zaks DPM (2011) Solutions for a cultivated planet. Nature 478:337-342

Frase P (2016) Four futures: life after capitalism. Verso Books, New York

Harari YN (2016) Homo Deus: a brief history of tomorrow. Random House, New York

Hebinck A, Vervoort JM, Hebinck P, Rutting L, Galli F (2018) Imagining transformative futures: participatory foresight for food systems change. Ecol Soc 23:2

Helbing D, Frey BS, Gigerenzer G, Hafen E, Hagner M, Hofstetter Y, Van Den Hoven J, Zicari RV, Zwitter A (2019) Will democracy survive big data and artificial intelligence? Towards digital enlightenment. Springer, Cham, pp 73-98

Kok K, Van Vliet M (2011) Using a participatory scenario development toolbox: added values and impact on quality of scenarios. $\mathbf{J}$ Water Clim Chang Lond 2(2-3):87-105. https://doi.org/10.2166/ wcc. 2011.032

Kok MTJ, Kok K, Peterson GD et al (2017) Biodiversity and ecosystem services require IPBES to take novel approach to scenarios. Sustain Sci 12:177. https://doi.org/10.1007/s11625-016-0354-8

Liu J, Mooney H, Hull V, Davis SJ, Gaskell J, Hertel T, Lubchenco J, Seto KC, Gleick P, Kremen C (2015) Systems integration for global sustainability. Science 347:1258832

Loorbach D, Frantzeskaki N, Avelino F (2017) Sustainability transitions research: transforming science and practice for societal change. Annu Rev Environ Resour 42:599-626

McPhearson T, Iwaniec D, Bai X (2017) Positive visions for guiding transformations toward desirable urban futures. Curr Opin Environ Sustain 22:33-40. https://doi.org/10.1016/j.cosust.2017.04.004

Millennium Ecosystem Assessment (MA) (2003) Ecosystems and human well-being: a framework for assessment. Island Press, Washington, DC

Millennium Ecosystem Assessment (MA) (2005) Ecosystems and human well-being: scenarios: findings of the Scenarios Working Group, Millennium Ecosystem Assessment. In: Carpenter SR, Pingali PL, Bennett EM, Zurek MB (eds) Island Press, Washington DC

Moore M, Tjornbo O, Enfors E, Knapp C, Hodbod J, Baggio JA, Norström A, Olsson P, Biggs D (2014) Studying the complexity of change: toward an analytical framework for understanding deliberate social-ecological transformations. Ecol Soc 19:54
Mueller ND, Gerber JS, Johnston M, Ray DK, Ramankutty N, Foley JA (2012) Closing yield gaps through nutrient and water management. Nature 490:254-257

Nakicenovic N, Alcamo J, Grubler A, Riahi K, Roehrl RA, Rogner HH, Victor N (2000) Special report on emissions scenarios (SRES), a special report of Working Group III of the intergovernmental panel on climate change. Cambridge University Press, Cambridge

O’Neill BC, Kriegler E, Riahi K, Ebi KL, Hallegatte S, Carter TR, Mathur R, van Vuuren DP (2014) A new scenario framework for climate change research: the concept of shared socioeconomic pathways. Clim Chang 122(3):387-400

Olsson P, Galaz V (2012) Social-ecological innovation and transformation. In: Nicholls A, Murdoch A (eds), Social innovation: blurring boundaries to reconfigure markets. Palgrave MacMillan, Basingstoke, pp 223-247. http://dx.doi.org/10.1057/9780230367098_10

Pereira LM, Hichert T, Hamann M, Preiser R, Biggs R (2018a) Using futures methods to create transformative spaces: visions of a good Anthropocene in southern Africa. Ecol Soc 23(1):19. https://www. ecologyandsociety.org/vol23/iss1/art19/. Accessed 8 July 2019

Pereira L, Bennett E, Biggs R, Peterson GD, McPhearson T, Norström A, Olsson P, Preiser R, Raudsepp-Hearne C, Vervoort J (2018b) Seeds of the future in the present: Exploring pathways for navigating towards "Good" Anthropocenes. In: Elmqvist T, Bai X, Frantzeskaki N, Griffith C, Maddox D, McPhearson T, Parnell S, Romero-Lankao P, Simon D, Watkins M (eds) Urban planet: knowledge towards sustainable cities, Chapter 16. Cambridge University Press, Cambridge, pp 327-350

Pereira LM, Karpouzoglou T, Frantzeskaki N, Olsson P (2018c) Designing transformative spaces for sustainability in socialecological systems. Ecol Soc 23(4):32. https://doi.org/10.5751/ ES-10607-230432

Peterson GD, Cumming GS, Carpenter SR (2003) Scenario planning: a tool for conservation in an uncertain World. Conserv Biol 17(2):358-366

Preiser R, Pereira LM, Biggs R (2017) Navigating alternative framings of human-environment interactions: variations on the theme of 'Finding Nemo'. Anthropocene 20:83-87

Riahi K, Van Vuuren DP, Kriegler E, Edmonds J, O'Neill BC, Fujimori S, Bauer N, Calvin K, Dellink R, Fricko O, Lutz W (2017) The shared socioeconomic pathways and their energy, land use, and greenhouse gas emissions implications: an overview. Glob Environ Chang 42:153-168

Rosa I, Pereira HM, Ferrier S, Alkemade R, Acosta LA, Akcakaya HR, Den Belder E, Fazel AM, Fujimori S, Harfoot M, Harhash KA, Harrison PA, Hauck J, Hendriks RJJ, Hernández G, Jetz W, Karlsson-Vinkhuyzen SI, Kim H, King N, Kok MTJ, Kolomytsev GO, Lazarova T, Leadley P, Lundquist CJ, Márquez JG, Meyer C, Navarro LM, Nesshöver C, Ngo HT, Ninan KN, Palomo MG, Pereira LM, Peterson GD, Pichs R, Popp A, Purvis A, Ravera F, Rondinini C, Sathyapalan J, Schipper AM, Seppelt R, Settele J, Sitas N, Van Vuuren D (2017) Multiscale scenarios for nature futures. Nat Ecol Evolut 1(10):1416-1419. https://doi.org/10.1038/s4155 9-017-0273-9

Schultz WL (2015) Mānoa: the future is not binary. APF Compass, Association of Professional Futurists, pp 4-8

Scoones I, Stirling A, Abrol D, Atela J, Charli-Joseph L, Eakin H, Ely A, Olsson P, Pereira L, Priya R, van Zwanenberg P, Yang L (2018) Transformations to sustainability. STEPS Working Paper 104, Brighton: STEPS Centre

Seppelt R, Manceur AM, Liu J, Fenichel EP, Klotz S (2014) Synchronized peak-rate years of global resources use. Ecol Soc 19(4):50. https://doi.org/10.5751/ES-07039-190450

Sharpe B, Hodgson A, Leicester G, Lyon A, Fazey I (2016) Three horizons: a pathways practice for transformation. Ecol Soc 21(2):47. https://doi.org/10.5751/ES-08388-210247Insight 
Steffen W, Richardson K, Rockström J, Cornell SE, Fetzer I, Bennett EM, Sörlin S (2015) Planetary boundaries: guiding human development on a changing planet. Science 347(6223). Retrieved from http://science.sciencemag.org/content/347/6223/1259855.abstract. Accessed 8 July 2019

Stover D (2018) Garlin Gilchrist: fighting fake news and the information apocalypse. Bull Atom Sci 74(4):283-288

Temper L, Walter M, Rodriguez I, Kothari A, Turhan E (2018) A perspective on radical transformations to sustainability: resistances, movements and alternatives. Sustain Sci 13(3):747-764

Tetlock PE (2005) Expert political judgment: How good is it? How can we know?. Princeton University Press, Princeton

Tilman D, Balzer C, Hill J, Befort BL (2011) Global food demand and the sustainable intensification of agriculture. Proc Natl Acad Sci USA 108:20260-20264

van Vuuren DP, Kok MTJ, Girod B, Lucas PL, de Vries B (2012) Scenarios in global environmental assessments: key characteristics and lessons for future use. Glob Environ Chang Hum Policy Dimens 22:884-895. https://doi.org/10.1016/j.gloen vcha.2012.06.001

Vanderbilt T (2015) Why futurism has a cultural blindspot. We predicted cell phones, but not women in the workplace. Nautilus Issue 028. http://nautil.us/issue/28/2050/why-futurism-has-a-cultu ral-blindspot. Accessed 8 July 2019

Vervoort JM, Thornton PK, Kristjanson P, Forch W, Ericksen PJ, Kok K, Ingram JSI, Herrero M, Palazzo A, Helfgott AES, Wilkinson
A, Havlik P, Mason-D'Croz D, Jost C (2014) Challenges to scenario-guided adaptive action on food security under climate change. Glob Environ Chang 28:383-394

Westley FR, McGowan K, Tjornbo O (eds) (2017) The evolution of social innovation: building resilience through sustainability transitions. Edward Elgar Publishing, Cheltenham, UK. http://dx.doi. org/10.4337/9781786431158

Wiebe K, Zurek M, Lord S, Brzezina N, Gabrielyan G, Libertini J, Loch A, Thapa-Parajuli R, Vervoort J, Westhoek H (2018) Scenario development and foresight analysis: exploring options to inform choices. Annu Rev Environ Resour 43:545-570. https:// doi.org/10.1146/annurev-environ-102017-030109

Wiek A, Iwaniec D (2014) Quality criteria for visions and visioning in sustainability science. Sustain Sci. https://doi.org/10.1007/s1162 5-013-0208-6

Willett W, Rockström J, Loken B, Springmann M, et al (2019) Food in the Anthropocene: the EAT-Lancet Commission on healthy diets from sustainable food systems. EAT Lancet Commission Healthy Diets Sustain Food Syst. https://doi.org/10.1016/s0140 $-6736(18) 31788-4$

Publisher's Note Springer Nature remains neutral with regard to jurisdictional claims in published maps and institutional affiliations. 